\title{
Study of the cytological features of bone marrow mesenchymal stem cells from patients with neuromyelitis optica
}

\author{
CHUNSHENG YANG ${ }^{1}$, YANG YANG $^{2}$, LI MA $^{3}$, GUANG-XIAN ZHANG $^{4}$, \\ FU-DONG SHI $^{1,5}$, YAPING YAN ${ }^{1}$ and GUOQIANG CHANG ${ }^{1}$
}

\begin{abstract}
${ }^{1}$ Department of Neurology, Tianjin Neurological Institute, Tianjin Medical University General Hospital; ${ }^{2}$ Department of Biochemistry and Molecular Biology, Tianjin Medical University, Tianjin 300052; ${ }^{3}$ Department of Neurosurgery and Neuro-Oncology, National Clinical Research Center for Cancer, Tianjin Medical University Cancer Institute and Hospital, Tianjin 300060, P.R. China; ${ }^{4}$ Department of Neurology, Thomas Jefferson University, Philadelphia, PA 19107; ${ }^{5}$ Department of Neurology, Barrow Neurological Institute, St. Joseph's Hospital and Medical Center, Phoenix, AZ 85013, USA
\end{abstract}

Received October 16, 2018; Accepted January 4, 2019

DOI: $10.3892 / \mathrm{ijmm} .2019 .4056$

\begin{abstract}
Neuromyelitis optica (NMO) is a refractory autoimmune inflammatory disease of the central nervous system without an effective cure. Autologous bone marrow-derived mesenchymal stem cells (BM-MSCs) are considered to be promising therapeutic agents for this disease due to their potential regenerative, immune regulatory and neurotrophic effects. However, little is known about the cytological features of BM-MSCs from patients with NMO, which may influence any therapeutic effects. The present study aimed to compare the proliferation, differentiation and senescence of BM-MSCs from patients with NMO with that of age- and sex-matched healthy subjects. It was revealed that there were no significant differences in terms of cell morphology or differentiation capacities in the BM-MSCs from the patients with NMO. However, in comparison with healthy controls, BM-MSCs derived from the Patients with NMO exhibited a decreased proliferation rate, in addition to a decreased expression of several cell cycle-promoting and proliferation-associated genes. Furthermore, the cell death rate increased in BM-MSCs from patients under normal culture conditions and an assessment of the gene expression profile further confirmed that the BM-MSCs from patients with NMO were more vulnerable to senescence. Platelet-derived growth factor (PDGF), as a major mitotic stimulatory factor for MSCs and a potent therapeutic
\end{abstract}

Correspondence to: Dr Guoqiang Chang, Department of Neurology, Tianjin Neurological Institute, Tianjin Medical University General Hospital, 154 Anshan Road, Tianjin 300052, P.R. China

E-mail: shanacgq@gmail.com

Abbreviations: BM-MNCs, bone marrow-derived mononuclear cells; MSCs, mesenchymal stem cells; NMO, neuromyelitis optica; PDGF, platelet-derived growth factor

Key words: neuromyelitis optica, mesenchymal stem cells, senescence, proliferation, cell cycle cytokine in demyelinating disease, was able to overcome the decreased proliferation rate and increased senescence defects in BM-MSCs from the patients with NMO. Taken together, the results from the present study have enabled the proposition of the possibility of combining the application of autologous BM-MSCs and PDGF for refractory and severe patients with NMO in order to elicit improved therapeutic effects, or, at the least, to include PDGF as a necessary and standard growth factor in the current in vitro formula for the culture of NMO patient-derived BM-MSCs.

\section{Introduction}

Neuromyelitis optica (NMO) is a severely disabling inflammatory disease of the central nervous system that predominantly affects the optic nerves and the spinal cord (1). The prevalence of NMO worldwide ranges from 0.5-4.4 cases per 100,000 $(2,3)$ and the mortality rate directly associated with NMO attacks ranges from 7 to $30 \%$, predominantly attributable to neurogenic respiratory failure (4-6). Most of the treatments for acute attacks and NMO relapses are targeted to controlling the symptoms, although large-scale randomized trials have been too scarce to allow optimization of the treatment strategies for NMO (7). Furthermore, immune modulatory and anti-inflammatory agents have not been demonstrated to influence the course of NMO progression and therefore are not suitable for curing chronic neurological disability. Therefore, novel treatment modalities to alleviate the disability resulting from NMO have evoked considerable interest. Much attention has been focused on restorative therapy, particularly the use of stem cells.

Mesenchymal stem cells (MSCs) are adult non-hematopoietic pluripotent cells with a high capacity to be induced to differentiate into other cell lines, including adipocytes, chondrocytes and stromal cells (8). Certain characteristics make MSCs attractive as therapeutic candidates, including innate pluripotency, the capacity to facilitate the repair of lesions through multiple avenues in immune regulation, angiogenesis and neurogenesis, and their immune privileged status (9). MSCs may be isolated from various sources, including bone marrow, adipose tissue (10), umbilical cord (11) and peripheral blood, 
among which the major and most frequently studied source is the bone marrow. Furthermore, a growing body of pre-clinical studies has consistently demonstrated that bone marrow-derived MSCs (BM-MSCs) are capable of safely ameliorating clinical outcomes of certain neurological degenerative diseases, including stroke (12) and multiple sclerosis $(13,14)$.

A recent paper published by the authors' laboratory revealed that the transplantation of autologous BM-MSCs exerted positive effects in the treatment of NMO (15). However, little is known about the cytological features of BM-MSCs from patients with NMO. In the present study, a comprehensive comparison of the cytological features of BM-MSCs from patients with NMO and healthy subjects was conducted. The results obtained will provide a general understanding of BM-MSCs derived from patients with NMO and may assist in the optimization of culture and cell proliferation protocols, thereby leading to improved MSC transplantation results.

\section{Materials and methods}

Patients. Informed consent was obtained from all participants in the present study and the study was approved by the Tianjin Medical University General Hospital Institutional Review Board and Ethics Committee (Tianjin, China). Patients with NMO were recruited between January 2016 and December 2017 from Tianjin Medical University General Hospital. The five patients (all female; patient characteristics are presented in Table SI) were enrolled on the basis of the following criteria: i) They conformed with the diagnostic criteria proposed by Wingerchuk et al (3) in 2007; ii) exclusion criteria included a history of diabetes, cardio- or cerebrovascular diseases and inflammatory, and autoimmune diseases other than NMO; iii) none of the patients had received corticosteroid or other immunosuppressant therapy within the last 4 weeks; and iv) all patients exhibited no other autoimmune diseases and all patients with NMO were monitored over a one year period (detailed information are described in Table SI). A total of five age-matched healthy female volunteers were enrolled as health controls.

Isolation and identification of BM-MSCs. Aliquots of 5-10 ml adult donor bone marrow aspirates were provided by the Department of Hematology of Tianjin Medical University General Hospital. Bone marrow-derived mononuclear cells (BM-MNCs) were isolated and cultured in Gibco ${ }^{\circledR}$ Dulbecco's Modified Eagle Medium/Nutrient Mixture F-12 (D-MEM/F-12 medium; Thermo Fisher Scientific, Inc., Waltham, MA, USA) supplemented with $10 \%$ fetal bovine serum (FBS; Hyclone, Chicago, IL, USA), $100 \mathrm{U} / \mathrm{ml}$ penicillin/streptomycin, $2 \mathrm{mM}$ L-glutamine (Sigma-Aldrich; Merck KGaA, Darmstadt, Germany), $2 \mathrm{ng} / \mathrm{ml}$ human basic fibroblast growth factor and $10 \mathrm{ng} / \mathrm{ml}$ human epidermal growth factor (PeproTech, Inc., Rocky Hill, NJ, USA). Platelet-derived growth factor-BB (PDGF-BB) was also purchased from PeproTech, Inc. Following culture at $37^{\circ} \mathrm{C}$ in a humid atmosphere with $5 \% \mathrm{CO}_{2}$ for 3 days, the culture medium was completely replaced and non-adherent cells were removed. When the cells had reached $\sim 80-85 \%$ confluence, the adherent cells were detached by treatment with $0.125 \%$ trypsin and $0.1 \%$ EDTA (Sigma-Aldrich; Merck KGaA), and put back into the medium at a 1:2 dilution under the same culture conditions.
Table I. Phenotype characteristics of bone marrow-mesenchymal stem cells.

\begin{tabular}{lccc}
\hline $\begin{array}{l}\text { Surface } \\
\text { marker }\end{array}$ & $\begin{array}{c}\text { Patients with } \\
\text { NMO (\%) }\end{array}$ & $\begin{array}{c}\text { Healthy } \\
\text { control (\%) }\end{array}$ & P-value \\
\hline CD29 & 98.35 & 99.01 & NS \\
CD34 & - & - & - \\
CD44 & 96.27 & 95.98 & NS \\
CD45 & - & - & - \\
CD73 & 99.15 & 98.79 & NS \\
CD90 & 95.30 & 96.12 & NS \\
CD105 & 92.28 & 93.19 & NS \\
CD166 & 94.25 & 95.42 & NS \\
\hline
\end{tabular}

$\mathrm{CD}$, cluster of differentiation; NS, not significant; NMO, neuromyelitis optica.

At passage 3, adherent cells were identified by surface markers with monoclonal antibodies cluster of differentiation (CD)29, CD166, CD44, CD73, CD34 and CD90 (BioLegend, Inc., San Diego, CA, USA), CD45 (BD Pharmingen; Becton, Dickinson and Company, Franklin Lakes, NJ, USA), CD105 (Abcam, Cambridge, MA, USA) using a FACS flow cytometer (BD Biosciences, Becton, Dickinson and Company; the details of all the antibodies are described in Table I).

Morphology of BM-MSCs. BM-MSCs were cultured in DMEM/F-12 medium and observed under an inverted light microscope. At the same time, BM-MSCs were stained for $\beta$-tubulin for the morphology examination. BM-MSCs were grown on glass chamber slides at $90 \%$ confluence and fixed with $4 \%$ paraformaldehyde at room temperature for $30 \mathrm{~min}$. Subsequently, the BM-MSCs were first permeated with cold acetone for $10 \mathrm{~min}$ and washed with ice-cold PBS. The BM-MSCs were then blocked with $5 \%$ bovine serum albumin (BSA; Sigma-Aldrich, Merck KGaA) in PBS at room temperature for $30 \mathrm{~min}$, followed by incubation with rabbit antihuman $\beta$-tubulin antibody (Thermo Fisher Scientific, Inc.) overnight at $4^{\circ} \mathrm{C}$. After three washes with ice-cold PBS, the BM-MSCs were incubated with goat tetramethylrhodamine-conjugated goat anti-rabbit immunoglobulin $\mathrm{G}$ secondary antibody (Thermo Fisher Scientific, Inc.; details of the antibodies are described in the Table II) at room temperature for $30 \mathrm{~min}$ and their nuclei were stained with $1 \mu \mathrm{g} / \mu \mathrm{l}$ 4',6-diamidino-2-phenylindole (DAPI) at room temperature for $10 \mathrm{~min}$. The cells were then washed twice with ice-cold PBS and the images were visualized using a fluorescence microscope (Nikon Corporation, Tokyo, Japan).

Cell proliferation assay. To assess the proliferation state of the BM-MSCs cells following the various treatments an MTT (Sigma-Aldrich; Merck KGaA) proliferation assay was performed according to the manufacturer's protocol. In brief, BM-MSCs cells were seeded into 96-well plates at a density of $2 \times 10^{4}$ cells $/ \mathrm{ml}$ for $1-4$ days. An aliquot of $20 \mu \mathrm{l}$ MTT labeling reagent $(5 \mathrm{mg} / \mathrm{ml})$ was added daily to each well and the plates were incubated at $37^{\circ} \mathrm{C}$ for $4 \mathrm{~h}$. The resulting formazan crystals 
Table II. Antibody information for fluorescence activated cell sorting.

\begin{tabular}{|c|c|c|c|}
\hline Name & Clone ID & Manufacturer; cat. no.; RRID & Dilution \\
\hline APC anti-human CD29 antibody & TS2/16 & $\begin{array}{l}\text { BioLegend, Inc. } 303007, \text { RRID:AB_314323; } \\
\text { mouse; monoclonal antibody }\end{array}$ & $\begin{array}{l}5 \mu \mathrm{l} \text { per million } \\
\text { cells in } 100 \mu \mathrm{l}\end{array}$ \\
\hline PE anti-human CD34 antibody & 561 & $\begin{array}{l}\text { BioLegend, Inc.; 343605; RRID:AB_1732033; } \\
\text { mouse; monoclonal antibody }\end{array}$ & staining volume \\
\hline FITC anti-human CD44 antibody & BJ18 & $\begin{array}{l}\text { BioLegend, Inc.; 338803; RRID:AB_1501204; } \\
\text { mouse; monoclonal antibody }\end{array}$ & \\
\hline PE anti-human CD166 antibody & $3 \mathrm{~A} 6$ & $\begin{array}{l}\text { BioLegend, Inc.; } 343903 \text {; RRID:AB_2289303; } \\
\text { mouse; monoclonal antibody }\end{array}$ & \\
\hline PerCP/Cyanine 5.5 anti-human CD73 & AD2 & $\begin{array}{l}\text { BioLegend, Inc.; } 344013 \text {; RRID:AB_2561756; } \\
\text { mouse; monoclonal antibody }\end{array}$ & \\
\hline FITC anti-human CD90 antibody & $5.00 \mathrm{E}+10$ & $\begin{array}{l}\text { BioLegend, Inc.; } 328107 \text {; RRID:AB_893438; } \\
\text { mouse; monoclonal antibody }\end{array}$ & \\
\hline $\begin{array}{l}\text { PerCP/Cyanine } 5.5 \text { anti-human } \\
\text { CD105 antibody }\end{array}$ & MEM-229 & Abcam; ab234265; mouse; monoclonal antibody & \\
\hline APC anti-human CD45 antibody & HI30 & $\begin{array}{l}\text { BD Biosciences; 560973; RRID:AB_10565969; } \\
\text { mouse; monoclonal antibody }\end{array}$ & \\
\hline
\end{tabular}

$\mathrm{CD}$, cluster of differentiation; FITC, fluorescein isothiocyanate; PE, phycoerythrin; APC, allophycocyanin.

were solubilized by adding $100 \mu 1$ DMSO per well and the plates were incubated at room temperature for $10 \mathrm{~min}$. The absorbance of formazan was measured at $575 \mathrm{~nm}$ and this was taken as the measure for the proliferation state of the cells. Trypan blue cell exclusion was also used at room temperature for $5 \mathrm{~min}$ to assess cell viability and the cell number with a light microscope.

Apoptosis of BM-MSCs. The apoptotic rate of the BM-MSCs was evaluated using a commercial fluorescein thiocyanate (FITC)-Annexin V apoptosis detection kit (Nanjing KeyGen Biotech Co., Ltd., Nanjing, China), as recommended by the manufacturer. BM-MSCs ( $5 \times 10^{5}$ cells) were harvested, washed and incubated in the Annexin V binding buffer. Subsequently, the BM-MSCs were stained with Annexin V-FITC and propidium iodide (PI), and flow cytometric analysis was then performed using a flow cytometer (BD FACSAria ${ }^{\mathrm{TM}}$ III) and the data were analyzed with FlowJo 7.6 software (FlowJo LLC, Ashland, OR, USA). Apoptotic cells were identified in the early (FITC-Annexin V positive, PI negative) and the late (FITC-Annexin V and PI double-positive) stages.

Reverse transcription-quantitative polymerase chain reaction $(R T-q P C R)$. TRIzol ${ }^{\circledR}$ reagent (Invitrogen; Thermo Fisher Scientific, Inc.) was used to isolate total RNA, following the manufacturer's protocol and the concentration of total RNA was measured using a spectrophotometer following treatment with DNase I (Invitrogen; Thermo Fisher Scientific, Inc.). A sample $(2 \mu \mathrm{g})$ of RNA was used for reverse transcription in a $20 \mu \mathrm{l}$ reaction containing EasyScript ${ }^{\circledR}$ reverse transcriptase kit (TransGen Biotech Co., Ltd., Beijing, China.). The thermal program consisted of $42^{\circ} \mathrm{C}$ for $30 \mathrm{~min}$, and then $85^{\circ} \mathrm{C}$ for $5 \mathrm{sec}$ to inactivate enzymes. RT-qPCR was performed using a Bio-Rad RT-PCR system instrument (Bio-Rad Laboratories, Inc., Hercules, CA, USA) with an SYBR ${ }^{\circledR}$-Green PCR kit
(Roche Diagnostics, Indianapolis, IN, USA). Genes involved in the cell cycle, proliferation and cell apoptosis were selected for investigation. Details of all the primers are described in Table III. The thermal cycling program consisted of $95^{\circ} \mathrm{C}$ for $10 \mathrm{~min}$, followed by 40 cycles of $15 \mathrm{sec}$ at $95^{\circ} \mathrm{C}$ and $60 \mathrm{sec}$ at $60^{\circ} \mathrm{C}$. Relative quantities of target genes were determined for unknown samples using the comparative threshold cycle $(\triangle \Delta \mathrm{Cq})$ method (16) and normalized against GAPDH as the control. Each test sample was amplified in three different wells with a $20 \mu 1$ reaction volume, following the manufacturer's protocol for each specific experiment and each test was repeated at least in triplicate.

Differentiation capacity of BM-MSCs. BM-MSCs were induced to differentiate into osteoblasts and adipocytes using the following procedure. The induction medium for osteogenesis was Gibco ${ }^{\circledR}$ Iscove's modified Dulbecco's medium (IMDM; Thermo Fisher Scientific, Inc.) supplemented with 10\% FBS, $0.1 \mu \mathrm{M}$ dexamethasone, $0.2 \mathrm{mM}$ ascorbic acid 2-phosphate and $10 \mathrm{mM}$ glycerol 2-phosphate (Sigma-Aldrich; Merck $\mathrm{KGaA}$ ). The induction medium for adipogenesis was IMDM supplemented with $10 \% \mathrm{FBS}, 1 \mu \mathrm{M}$ dexamethasone, $0.5 \mathrm{mM}$ 3-isobutyl-1-methylxanthine, $10 \mu \mathrm{g} / \mathrm{ml}$ insulin and $60 \mu \mathrm{M}$ indomethacin (Sigma-Aldrich; Merck KGaA). After 3 days, the culture medium was completely replaced and the medium was subsequently changed twice weekly thereafter. After the predetermined culture time had elapsed, adipocytes were stained with Oil Red $\mathrm{O}$ at room temperature for $30 \mathrm{~min}$; the osteoblasts were identified using alkaline phosphatase (ALP) and Alizarin Red $\mathrm{S}$ assays were performed at room temperature in the dark for 50 min (Sigma-Aldrich; Merck KGaA).

Western blot analysis. The total proteins of the BM-MSCs were extracted with Pierce ${ }^{\mathrm{TM}}$ IP Lysis buffer (Thermo Fisher 


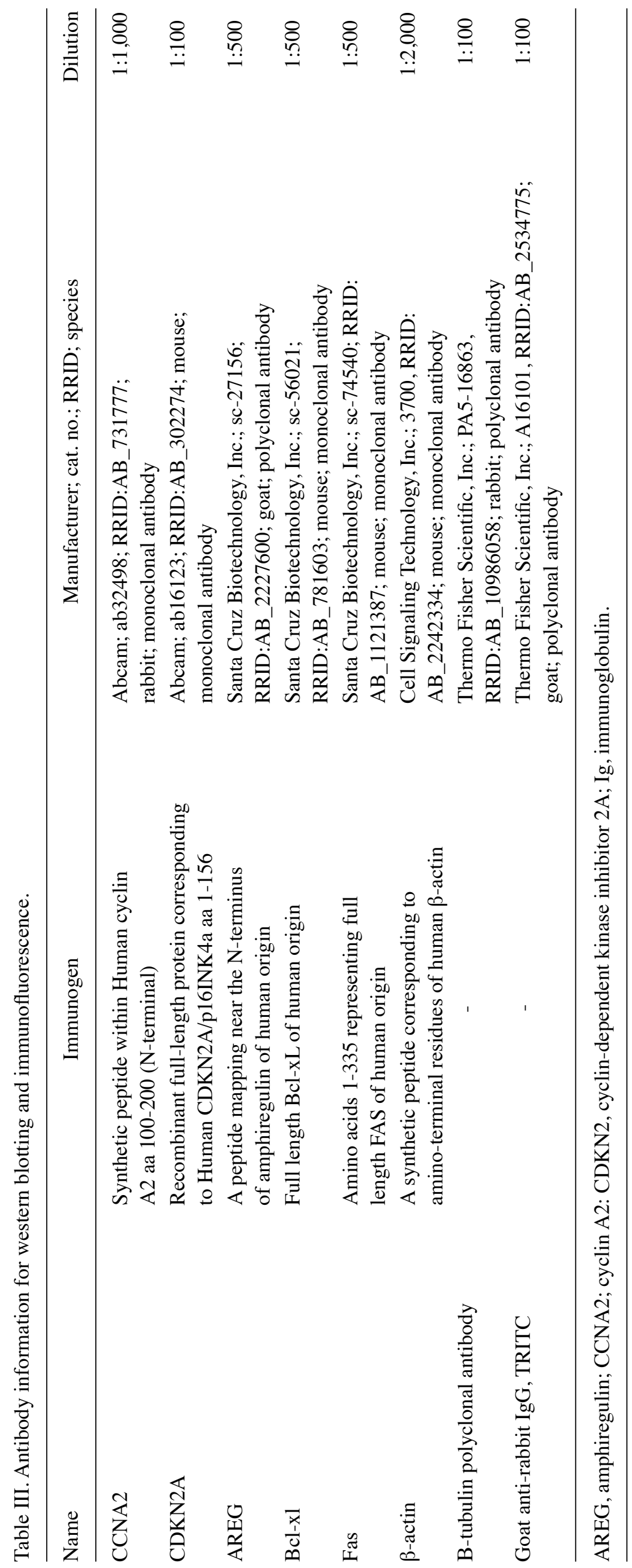


Scientific, Inc.) and the concentration was determined with bicinchoninic acid (BCA) methods with a BCA protein assay kit (Beijing Solarbio Science \& Technology Co., Lt., Beijing, China). The proteins were separated using 10\% SDS-PAGE and $15 \mu \mathrm{g}$ protein were loaded in each lane. Subsequently, the proteins were transferred electrophoretically to a polyvinylidene difluoride membranes (Merck KGaA). The membranes were blocked with $5 \%$ defatted milk at room temperature for $1 \mathrm{~h}$ and then incubated with the primary antibodies overnight. The next day, the membranes were incubated with the HRP-conjugated secondary antibodies for $1 \mathrm{~h}$. Protein bands were detected using an Amersham ECL Western blotting detection kit (GE Healthcare Life Sciences, Little Chalfont, UK). The protein bands were statistically analyzed with ImageJ 1.4 software (National Institutes of Health, Bethesda, MD, USA). For western blotting analysis, the $\beta$-actin antibody (used as the loading control) was purchased from Santa Cruz Biotechnology, Inc., (Dallas, TX, USA); the antibodies against cyclin A2 (CCNA2), cyclin-dependent kinase inhibitor 2A (CDKN2A), amphiregulin (AREG) and Bcl-xl were from Cell Signaling Technology, Inc., (Danvers, MA, USA); and the anti-Fas antibody came from R\&D Systems, Inc., (Minneapolis, MN, USA). All antibodies are described in further detail in Table II.

Statistical analysis. Each experiment was repeated at least three times. All data are presented as the mean \pm standard deviation. The difference between means was statistically analyzed using a t-test. All statistical analyses were performed using GraphPad Prism 6 software (GraphPad Software, Inc., La Jolla, CA, USA). P $<0.05$ was considered to indicate a statistically significant difference.

\section{Results}

NMO patient-derived BM-MSCs exhibitnormaldifferentiation capacity and a similar morphology compared with BM-MSCs derived from healthy controls. Aliquots of 5-10 ml adult donor bone marrow aspirates (five from patients with NMO and five from age- and sex-matched healthy subjects) were provided by the Department of Hematology of Tianjin Medical University General Hospital. After isolation, BM-MSCs at passage 3 were harvested to analyze their immunophenotype using flow cytometric analysis. BM-MSCs from patients with NMO and healthy controls were revealed to express CD105, CD73, CD90, CD29, CD44 and CD166, although they lacked expression of CD34 and CD45 (Table IV). All the BM-MSCs formed a monolayer of bipolar spindle-like cells, with a 'whirlpool-like' array. However, certain BM-MSCs from the patients with NMO were observed to be aberrant, with an irregular and ragged appearance following staining with $\beta$-tubulin under a fluorescence confocal microscope. Compared with the elongated morphology of the BM-MSCs from the healthy controls, certain BM-MSCs from patients with NMO also exhibited a 'cobblestone'-like' appearance (Fig. 1A).

The differentiation capabilities of BM-MSCs were subsequently investigated following induction with the differently conditioned media. BM-MSCs were able to differentiate into osteoblasts and adipocytes, as tested by positive staining of ALP and Alizarin Red S (for osteoblasts), and Oil Red O (for adipocytes). The results revealed that the BM-MSCs from the healthy controls and the patients with NMO were easily induced to differentiate into osteoblasts and the adipocyte lineage (Fig. 1B). There appeared to be no obvious differences in the differentiation capability between BM-MSCs from either the healthy controls or the patients with NMO. These data indicated that there was little discrepancy in morphology between BM-MSCs from healthy control subjects and the patients with NMO, since all the BM-MSCs had very similar differentiation capabilities.

NMO patient-derived BM-MSCs exhibit decreased proliferative capability in vitro. The proliferative capability of the BM-MSCs was measured using a non-radioactive MTT assay method. The extent of cell proliferation was measured following culture for $0,1,2,3$ and 4 days, in a regular MSC culture medium. As presented in Fig. 2A, the proliferation rate of BM-MSCs from the patients with NMO was decreased compared with the healthy controls from day 3. However, following 4 days of culture, the proliferation of the BM-MSCs from the patients with NMO was significantly decreased $(\mathrm{P}<0.05)$. In addition, along with the proliferation assay, the mRNA expression levels of an array of cell cycle- and proliferation-associated genes in the BM-MSCs from the patients with NMO and healthy controls were detected by RT-qPCR (Fig. 2B and C). These experiments revealed that the expression levels of AREG and CCNA2 were significantly decreased in BM-MSCs from the patients with NMO compared with the healthy controls $(\mathrm{P}<0.05)$, whereas the expression of CDKN2A significantly increased in the patient group $(\mathrm{P}<0.05)$. Changes in the protein levels of the above genes revealed a similar tendency. Three experimental subjects were randomly selected from the NMO patient group and the healthy subject group, respectively, and these exhibited the same tendency (Fig. 3A and $\mathrm{B}$ ). These data suggested that the proliferative capabilities of BM-MSCs from the patients with NMO were lower compared with those of BM-MSCs from the healthy controls.

NMO patient-derived BM-MSCs exhibit increased senescence in vitro. The viability of BM-MSCs was subsequently compared between the patients with NMO and the healthy controls, as indicated by the apoptotic rate of BM-MSCs under normal culture conditions. As presented in Fig. 4, the apoptotic rate of BM-MSCs from the patients with NMO was three times higher compared with the healthy controls. In addition, the expression levels of an array of cell apoptosis and cell death-associated genes were compared between the two groups. Of the genes assessed, the expression of Fas was revealed to be significantly increased $(\mathrm{P}<0.05)$, whereas that of the pro-survival gene Bcl-xl was significantly decreased in BM-MSCs from the patients with NMO at the mRNA and the protein levels $(\mathrm{P}<0.01$; Fig. 4B-D). These data suggested that senescence may be increased in the BM-MSCs from patients with NMO compared with the healthy controls. Furthermore, the BM-MSCs from patients with NMO were at a disadvantage in terms of their self-renewal capability.

PDGF-BB can stimulate cell proliferation and overcome the senescence disadvantage, of BM-MSCs from patients with NMO. Several growth factors and cytokines have been considered to be critical factors regulating MSC proliferation, 
Table IV. Quantitative-polymerase chain reaction primer sequences.

Genes $\quad$ Sequence $\left(5^{\prime}-3^{\prime}\right)$

\section{AIF}

ATM

BAX

Bcl-xl

Caspase 3

Caspase 8

\section{CYCS}

FADD

Fas

FasL

TNFSF10

TRADD

CCNA2

CCNB 1

CCNE2

CDC2

CDC20

CDK4

CDK6

CDKN2A

ORC5L

SMAD3

YWHAZ

AREG

CXCL1
F: ATCTACAGGTGCTTCTGG R: GGCCTTTTTCTGTTTCTG F: GTGCCAGAATGATAAAGC R: GAAGCCAATACTGGACTG F: GACGGCAACTTCAACTGG R: GGAGGAAGTCCAATGTCC F: GCTGGTGGTTGACTTTCT R: TCCATCTCCGATTCAGTC F: TCTGGAATATCCCTGGAC R: ATGTTTCCCTGAGGTTTG F: CCTGAGCCTGGACTACAT R: TCAGGAAGGACAGATTGC F: GCCCCTGGATACTCTTAC R: GCCCTTTCTTCCTTCTTC F: GGTGTCGTCCAGCCTGTC R: TCCAGGTCGTTCTGCTCC F: GATGACCGTCGCTGGAAG R: CCATCGTGTGTGCCTGCT F: CTCCAGGCACAGTTCTTC R: GTGGTTCCCTCTCTTCTT F: ATGGCTATGATGGAGGTC R: AGAAACAAGCAATGCCAC F: CAAAATGGGCACGAAGAG R: CGGTGGATCTTCAGCATC F: ACAGTAAACAGCCTGCGTTC R: CAGGGCATCTTCACGCTCTA F: GTGCCAGTGCCAGTGTCTGA R: CCATTGGGCTTGGAGAGGCA F: TGTAACAATCATCTCCTGGC R: GGAGGTAAAATGGCACAAGG F:TAGAAAGTGAAGAGGAAGGG R: TACTGACCAGGAGGGATAGA F:CAAAGCCAAGGAAGCCGCAG R: TCACCGCCAGGTTTGCTAGG F: CGGTGCCTATGGGACAGTGT R: CAGTCGCCTCAGTAAAGCCA F: TGCTGAGGCACCTGGAGACC R: TCAGTGGGCACTCCAGGCTC F: TTCCTGGACACGCTGGTGGT R: GGTTACTGCCTCTGGTGCCC F: ATACTGGATGCTTTGAGCCG R: TAGGCAGCATAGAAATCAGC F: GCGGTCAAGAGCCTGGTCAA R: CACAGGCGGCAGTAGATGAC F: ATGTTGTAGGAGCCCGTAGG R: TTTGCTCTCTGCTTGTGAAG F: GGTGCTGTCGCTCTTGAT R: GCATTTCACTCACAGGGG F: CCCAAACCGAAGTCATAG R: CCTTCTGGTCAGTTGGAT
Table IV. Continued

\begin{tabular}{ll}
\hline Genes & \multicolumn{1}{c}{ Sequence (5'-3') } \\
\hline DLG7 & F: ACCTGGTCCAAGACAAAC \\
& R: CTGCTTTGCTGCTTGAGT \\
DLGAP5 & F: CTACTCAAGCAGCAAAGC \\
& R: GGCAGGTCTTCCTTTACT \\
KITLG & F: GTCATTGTTGGATAAGCG \\
& R: TCTGGGCTCTTGAATGAT \\
\hline
\end{tabular}
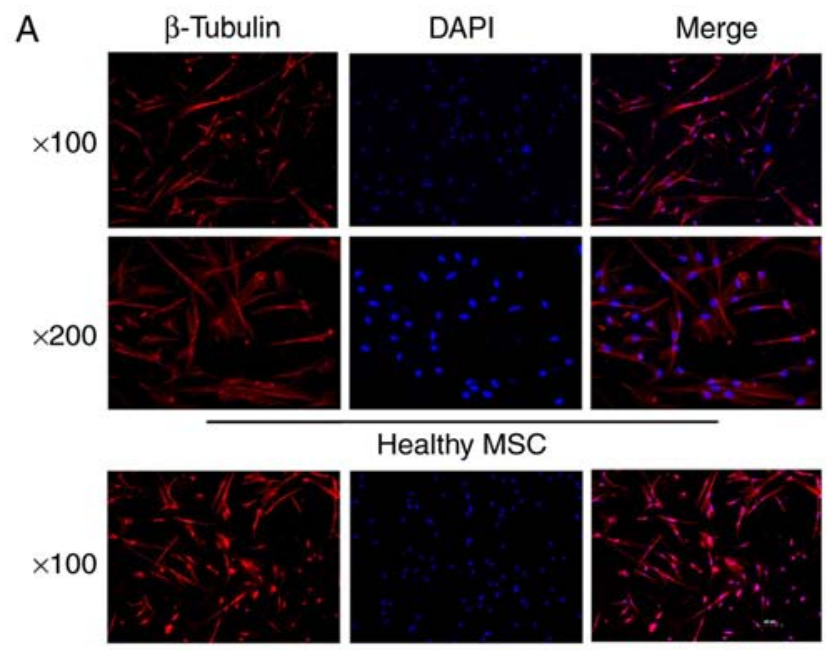

Healthy MSC

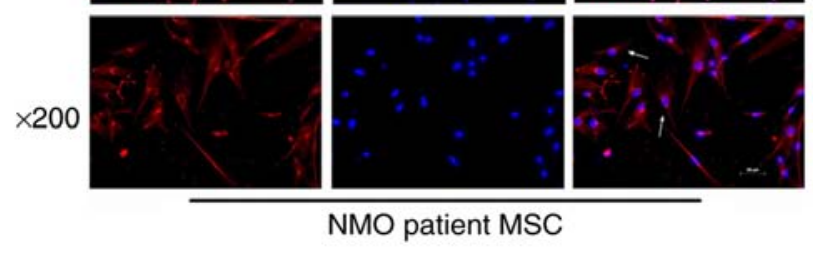

B

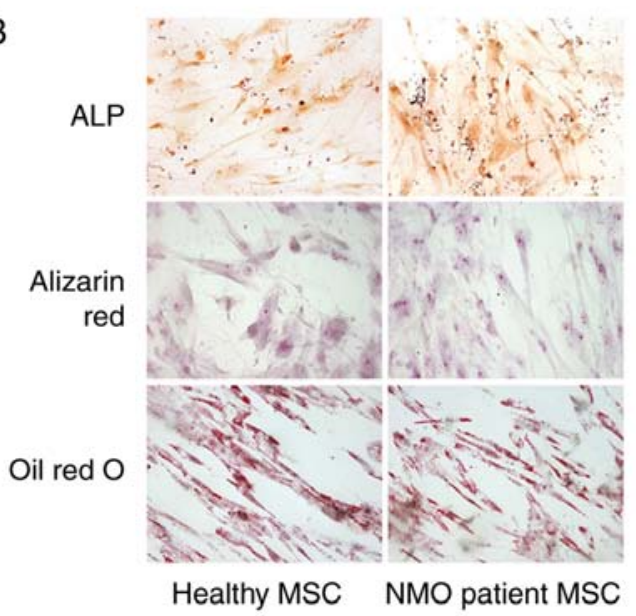

Figure 1. Representative morphological and differentiation images of BM-MSCs derived from patients with NMO and healthy controls. (A) The morphology of BM-MSCs is presented following staining with $\beta$-tubulin (red coloration). The nuclei of BM-MSCs were stained with DAPI (indicated by the blue staining). The arrows indicate the 'cobblestone-like' appearance of BM-MSCs from the patients with NMO. (B) The osteogenic differentiation capacity of BM-MSCs was detected by positive staining of ALP (upper panel) and Alizarin Red (middle panel). The adipogenic differentiation capacity of BM-MSCs was detected by positive staining of Oil Red O (lower panel). BM-MSC, bone marrow-derived mesenchymal stem cell; NMO, neuromyelitis optica; DAPI, 4',6-diamidino-2-phenylindole; ALP, alkaline phosphatase. 
A

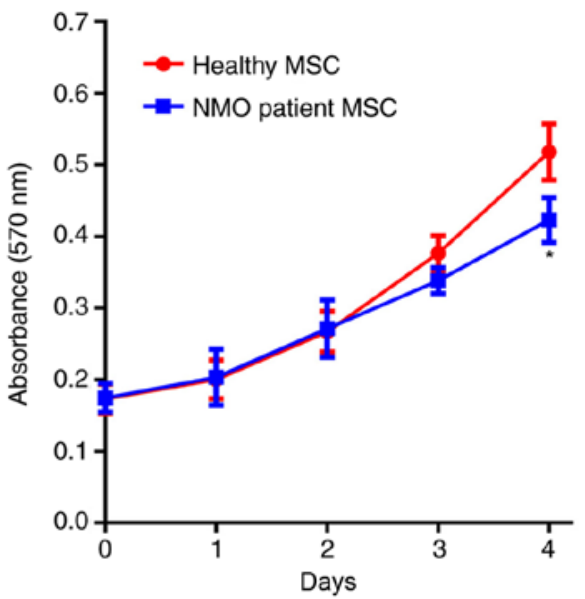

B

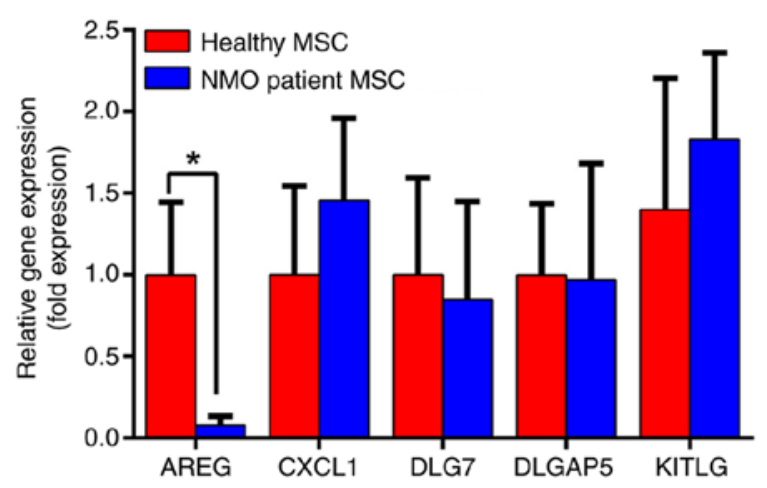

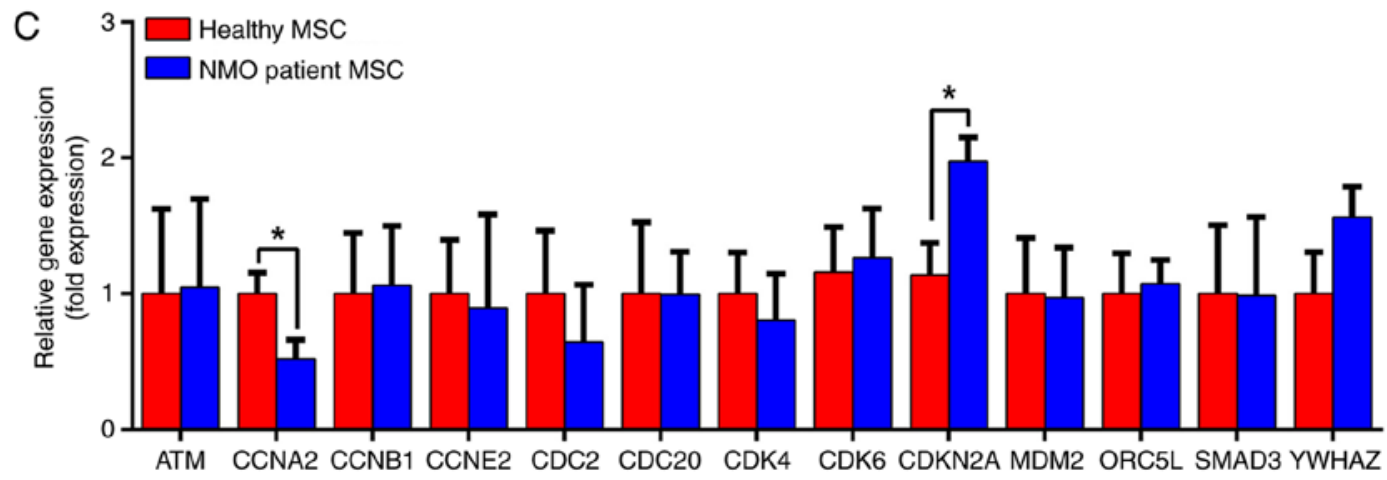

Figure 2. Expression patterns of proliferation and cell cycle-associated genes of BM-MSCs derived from patients with NMO and healthy controls. (A) Proliferation rate of the BM-MSCs was detected using an MTT assay at the culture time points indicated. (B) The cell proliferation-associated gene profile was determined using RT-qPCR. (C) The cell cycle-associated gene profile was determined using RT-qPCR. " $\mathrm{P}<0.05$ vs. the healthy control. BM-MSC, bone marrow-derived mesenchymal stem cell; NMO, neuromyelitis optica; RT-qPCR, reverse transcription-quantitative polymerase chain reaction.

migration and differentiation, among which PDGF is regarded as the most potent mitotic stimulatory factor $(17,18)$. PDGFs are disulfide-linked homodimers or heterodimers, consisting of several 12.0-13.5 $\mathrm{kDa}$ polypeptide chains designated as the PDGF-A, -B, -C and -D chains and the five naturally occurring PDGFs are PDGF-AA, PDGF-BB, PDGF-AB, PDGF-CC and PDGF-DD (18). Considering that PDGF-BB is the major growth factor in bone matrix and its safety and effectiveness have been verified in a number of clinical trials $(19,20)$, it seemed logical during these experiments to supplement the NMO BM-MSC culture medium with PDGF-BB in order to optimize the BM-MSCs' biological properties. The MTT assay experiment revealed that $20 \mathrm{ng} / \mathrm{ml}$ PDGF-BB was able to significantly promote the proliferation rate of BM-MSCs from patients with $\mathrm{NMO}$ on days 3 and $4(\mathrm{P}<0.05$; Fig. 5A). Furthermore, the cytometric images indicated that the apoptotic rate of the NMO patient group was decreased from $9.745 \pm 0.245 \%$ to $3.672 \pm 0.128 \%$ (P $<0.01 ;$ Fig. $5 \mathrm{~B}$ ). Additionally, improvements at the molecular level were also confirmed by RT-qPCR. As presented in Fig. 5C, the expression levels of AREG, CCNA2 and Bcl-xl were significantly increased $(\mathrm{P}<0.01)$; conversely, the expression levels of CDKN2A and Fas were significantly decreased (all $\mathrm{P}<0.05$ ). The protein expression levels following PDGF-BB treatment in MSC cells from the identical patients were also examined. Three patients were selected and the protein expression levels of AREG, CCNA2 and Bcl-xl were revealed to be significantly increased in the patients with NMO MSC with PDGF $(\mathrm{P}<0.05)$, whereas
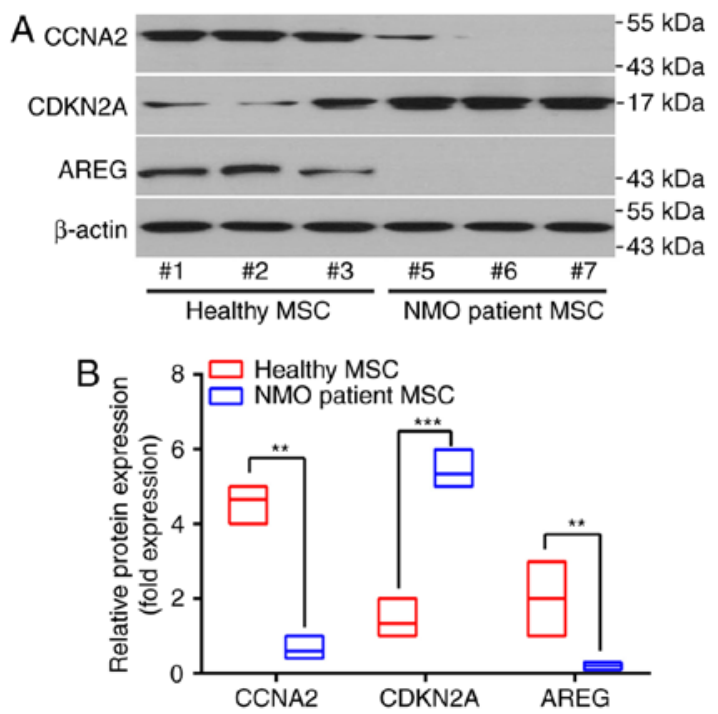

Figure 3. Different protein expression patterns of BM-MSCs from patients with NMO and healthy controls. (A) Representative results of the protein expression patterns of AREG, CCNA2 and CDKN2A, as determined by western blot analysis, are presented. Samples \#1, \#2 and \#3 were taken from the healthy volunteers, whereas samples \#5,\#6, \#7 were from the NMO patient group. (B) The relative protein expression levels of AREG, CCNA2 and CDKN2A. For the western blot analysis, the protein bands were statistically analyzed with ImageJ software and $\beta$-actin was used as an internal control. Results are presented as the mean \pm standard deviation of three independent experiments and each experiment was performed in triplicate. ${ }^{* * *} \mathrm{P}<0.01$ and ${ }^{* * *} \mathrm{P}<0.001$ vs. the healthy control. BM-MSC, bone marrow-derived mesenchymal stem cell; NMO, neuromyelitis optica; AREG, amphiregulin; CCNA2, cyclin A2; CDKN2, cyclin-dependent kinase inhibitor 2A. 

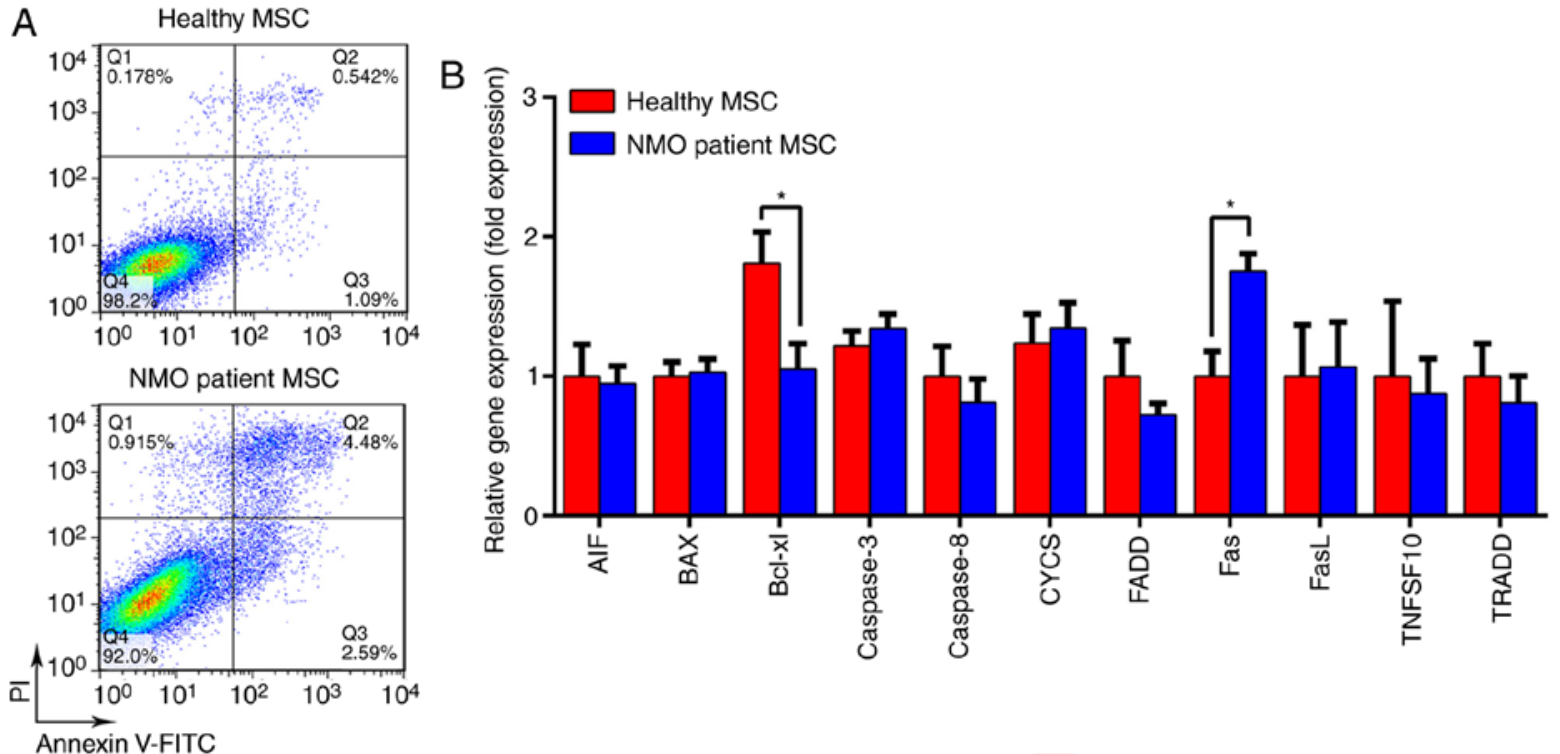

Annexin V-FITC
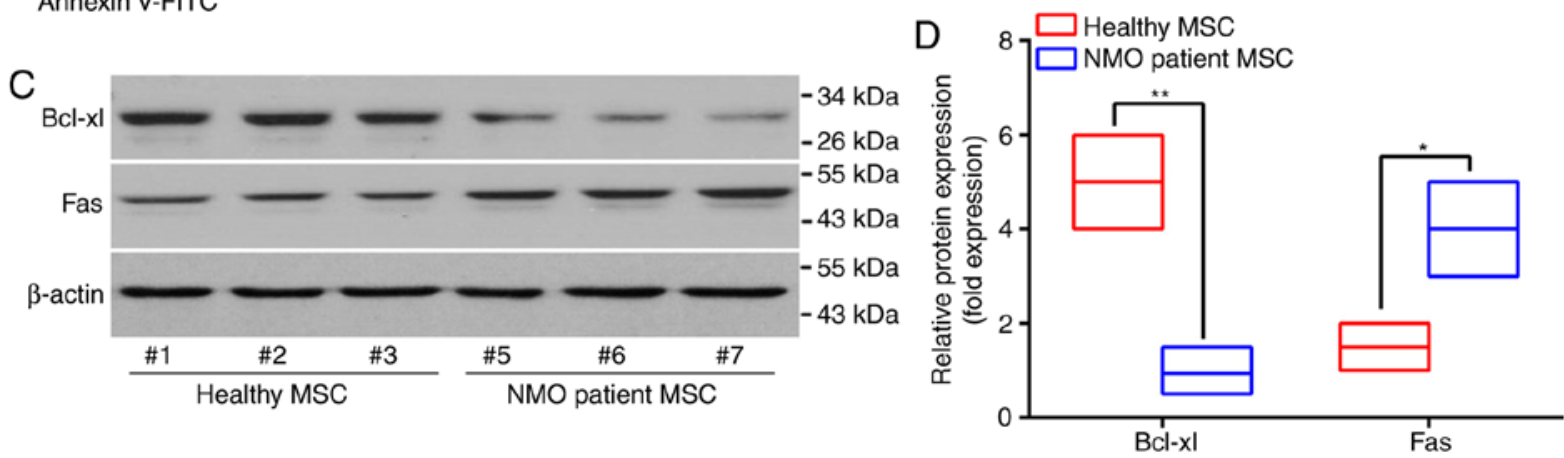

Figure 4. The apoptotic rate and apoptosis-associated gene expression patterns of BM-MSCs from patients with NMO and healthy controls. (A) Representative dot plots of the apoptotic rate of BM-MSCs are presented. (B) The global apoptosis-associated gene expression profile of BM-MSCs was determined using RT-qPCR. (C) The protein expression levels of Bcl-xl and Fas were determined by western blotting and representative results are presented. Samples \#1, \#2 and \#3 were taken from the healthy volunteers, whereas samples \#5, \#6, \#7 were from the NMO patient group. (D) Relative protein expression levels of Bcl-xl and Fas. For the western blot analysis, the protein bands were statistically analyzed with ImageJ software and $\beta$-actin was used as an internal control. Results are presented as the mean \pm standard deviation of three independent experiments and each experiment was performed in triplicate. ${ }^{*} \mathrm{P}<0.05$ and ${ }^{* * *} \mathrm{P}<0.01$ vs. the healthy controls. BM-MSC, bone marrow-derived mesenchymal stem cell; NMO, neuromyelitis optica; RT-qPCR, reverse transcription-quantitative polymerase chain reaction; FITC, fluorescein isothiocyanate; PI, propidium iodide.

the expression levels of Fas and CDKN2A were significantly decreased $(\mathrm{P}<0.01$; Fig. $6 \mathrm{~A}$ and $\mathrm{B})$.

\section{Discussion}

NMO is a humoral immunity-mediated inflammatory demyelinating disease that preferentially targets the spinal cord and optic nerves (21). NMO is associated with a generally poor prognosis and the permanent myelin losses that precede and characterize the progressive stage of NMO remain untreatable (22). Stem cell transplantation has been considered to be a potential treatment method for neurological disorders due to the multifaceted roles of stem cells. Greco et al (23) applied hematopoietic stem cells to treat NMO and discovered that the treatment was able to reduce neuroinflammation and halt the progression of disability. By contrast, Matiello et al (24) demonstrated that autologous hematopoietic stem cell transplantation was unable to prevent the relapse of NMO (24). These results provide the foresight that caution is necessary in terms of selecting an appropriate type of stem cells to treat NMO.

MSCs have been extensively studied as cellular therapies due to their various modes of action. MSCs exhibit numerous characteristics, including immune modulatory, neurotrophic (25) and repair-promoting properties, which make them attractive candidates for treating various degenerative neurological diseases, including stroke $(26,27)$, multiple sclerosis $(13,28)$ and Parkinson's disease $(29,30)$. In 2012, Lu et al (31) reported that four out of five patients with NMO demonstrated therapeutic improvements following receiving human umbilical cord MSC therapy (31). However, the use of these allogeneic cells is associated with ethical concerns and the possibility of immunological rejection. Although the authors' recent clinical pilot observation revealed that the infusion of autologous MSCs provided beneficial effects in terms of lowering the relapse rate and disability in patients with NMO (15), further studies are required in order to focus on the cytological features of patient-derived BM-MSCs that may influence the therapeutic effects on patients with NMO. Therefore, the present study aimed to demonstrate whether the biological properties of BM-MSCs from patients with NMO are different from those of BM-MSCs taken from healthy control subjects. The results obtained revealed that there was no difference in the immune phenotype markers of BM-MSCs, comparing between the patients with NMO and healthy 
A

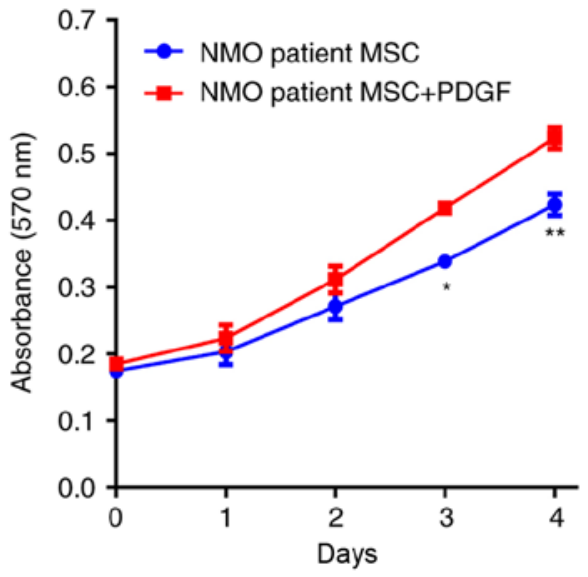

B
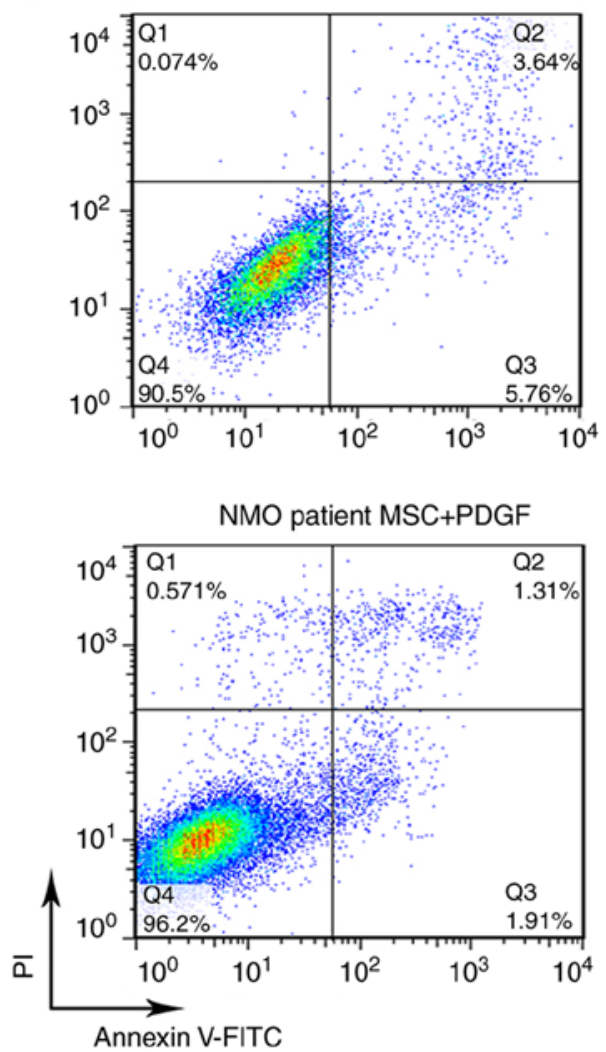

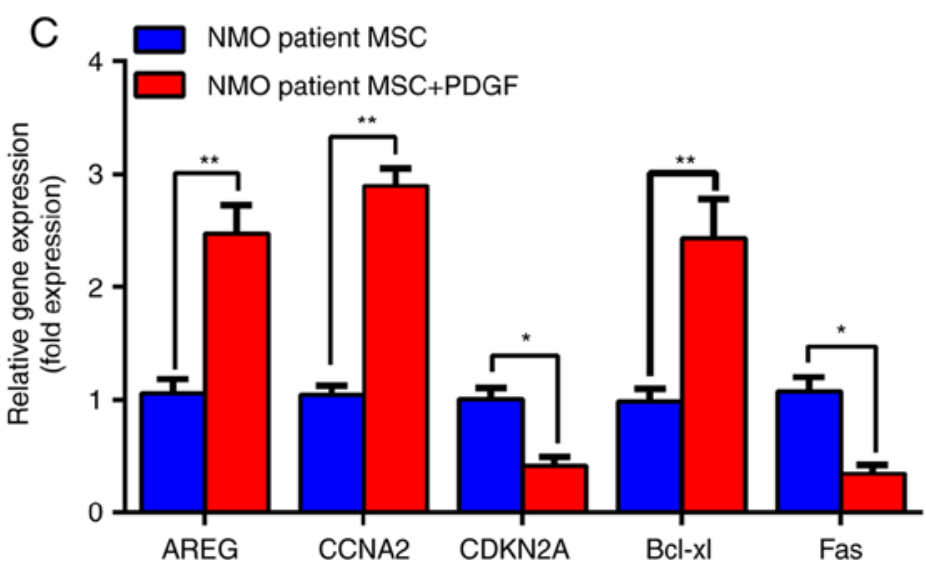

Figure 5. PDGF-BB can stimulate proliferation and overcome the senescence disadvantage, of BM-MSCs from patients with NMO. (A) The proliferation curve of BM-MSCs from patients with NMO treated with PDGF-BB $(20 \mathrm{ng} / \mathrm{ml})$ is presented. (B) Representative dot plots demonstrating the apoptotic rate of BM-MSCs from patients with NMO treated with PDGF-BB $(20 \mathrm{ng} / \mathrm{ml})$. (C) mRNA levels of AREG, CCNA2, CDKN2A and Fas genes in BM-MSCs from patients with NMO treated with PDGF-BB (20 ng/ml), as determined using RT-qPCR are presented. ${ }^{*} \mathrm{P}<0.05$ and ${ }^{* *} \mathrm{P}<0.01$ vs. the controls. BM-MSC, bone marrow-derived mesenchymal stem cell; NMO, neuromyelitis optica; RT-qPCR, reverse transcription-quantitative polymerase chain reaction; AREG, amphiregulin; CCNA2, cyclin A2; CDKN2, cyclin-dependent kinase inhibitor 2A; PGDF-BB, platelet-derived growth factor-BB; FITC, fluorescein isothiocyanate; PI, propidium iodide.

controls. The appearances of certain of the BM-MSCs from the patients with NMO were revealed to be slightly aberrant, even though they exhibited a normal differentiation capability; however, the BM-MSCs from patients did reveal decreased proliferative capacity and increased senescence.

In addition to the observed biological phenomena, it was determined that an array of cell cycle, proliferation and apoptosis-associated gene expression profiles varied between the BM-MSCs derived from the patients with NMO and the healthy controls. Decreased expression levels of AREG have been demonstrated to induce abnormalities of homeostasis and to decrease cell proliferation (32). In addition, CDKN2A is a gene that can induce arrested cell growth. The activation of CDKN2A may inhibit the cell cycle transition from G1 to the $\mathrm{S}$ phase by inhibiting cyclin-dependent kinases (CDKs). CCNA2 belongs to the cyclin family that regulates the $\mathrm{S}$ phase of cell cycle progression by interacting with CDKs and decreased CCNA2 may arrest the cell cycle at $S$ phase. Therefore, aberrant expression of CKDN2A and CCNA2 may lead to maladjusted cell growth. In the present study, the expression levels of Fas in the patients with NMO were increased compared with those of healthy controls. The Fas receptor is a death receptor on the surface of cells that initiates programmed cell death when bound to its ligand, Fas-L and an increasing number of reports have demonstrated that Fas overexpression is associated with apoptosis and cell senescence (33-35). Bcl-xL is a canonical anti-apoptotic protein in the Bcl-2 family. Bcl-xL inhibits Bak or Bax activation, which is an essential event for apoptosis and senescence execution $(36,37)$.

PDGF signaling pathways have long been demonstrated to be involved in pre- and post-natal vasculogenesis and/or angiogenesis. PDGFs are potent mitogens for MSCs and are involved in their growth and differentiation. PDGF isoforms exert their biological effects via the activation of two tyrosine kinase receptors, PDGF receptor- $\alpha$ (PDGFR)- $\alpha$ and PDGFR- $\beta$, which are abundantly expressed on MSCs (17). Studies have been published on a large number of successful applications of PDGF-BB-based therapies for various types of maladies, including tendon and bone fracture repairs, and demyelinating disease $(20,38)$. For example, Chen et al (19) performed PDGF-BB-based stem cell gene therapy to improve bone strength in hematopoietic stem cell transplantation subjects and in their in vivo model the proliferation of BM-MSCs increased significantly compared with the control group (19).

In order to find the potential mechanism of different cytological features of BM MSCs from patients with NMO and healthy subjects, 28 genes involved in the cell cycle, proliferation and cell apoptosis were screened with the RT-qPCR 


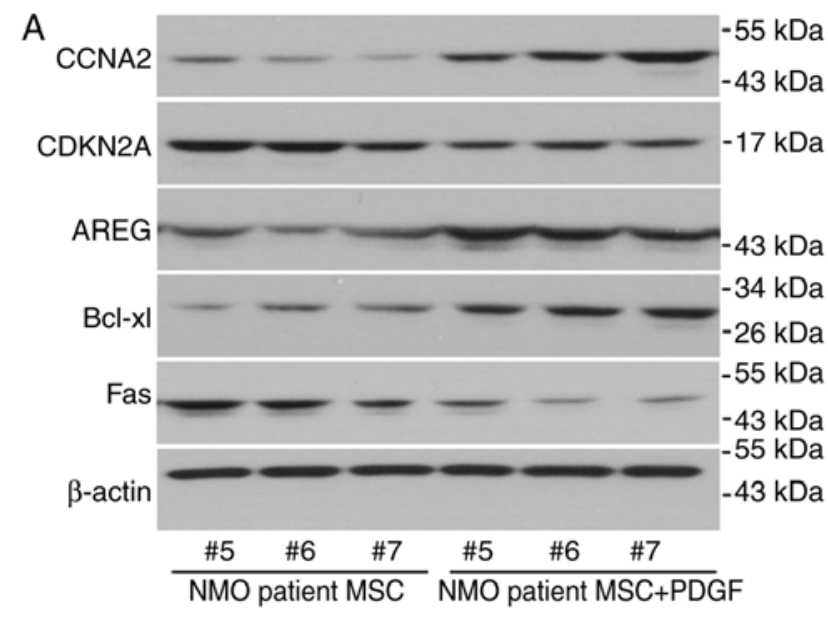

$\mathrm{B}$

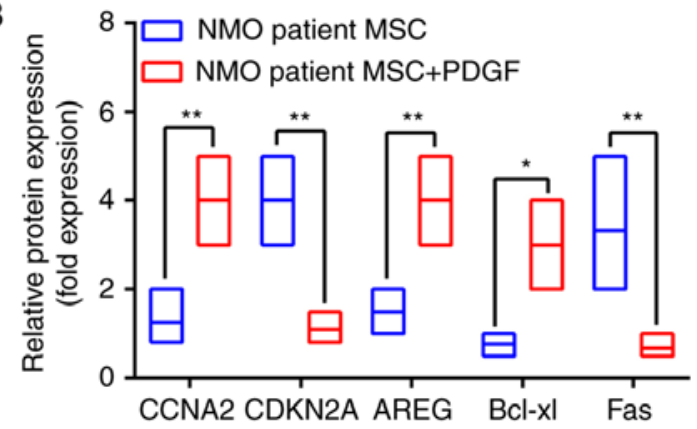

Figure 6. PDGF-BB is able to rescue the protein expression levels of the proliferation and proliferation-associated genes of interest studied in the BM-MSCs from patients with NMO. (A) The protein levels of AREG, CCNA2, CDKN2A and Fas in BM-MSCs from patients with NMO treated with PDGF-BB $(20 \mathrm{ng} / \mathrm{ml})$ were detected using western blot analysis Representative results are presented. The protein levels of the BM-MSCs from samples \#5, \#6 and \#7 (pertaining to the patients with NMO) were assessing by western blotting following treatment with PDGF-BB. (B) Relative protein expression levels of AREG, CCNA2, CDKN2A, Bcl-xl and Fas. For the western blot analysis, the protein bands were statistically analyzed with ImageJ software and $\beta$-actin was used as an internal control. Results are presented as the mean \pm standard deviation of three independent experiments and each experiment was performed in triplicate. ${ }^{*} \mathrm{P}<0.05$ and ${ }^{* *} \mathrm{P}<0.01$ vs. the healthy controls. PGDF-BB, platelet-derived growth factor-BB; BM-MSC, bone marrow-derived mesenchymal stem cell; NMO, neuromyelitis optica; AREG, amphiregulin; CCNA2, cyclin A2; CDKN2, cyclin-dependent kinase inhibitor 2A; PDGF, platelet-derived growth factor.

method and found the genes, which were differentially expressed in two kinds of BM-MSCs, could be divided into two groups: Cell cycle associated genes like AREG, CCNA2 and CDKN2A, and cell program death associated genes like Bcl-xl and Fas. The results of the present study demonstrated the expression of CCNA2 and Fas increased, and the expression of CDKN2A and Bcl-xl was decreased in BM-MSCs from patients with NMO. A wide range of evidence indicates that CCNA2 is implicated in the initiation and progression of DNA synthesis and involved in the G2/M transition, and CDKN2A could inhibit the cell cycle through blocking transition from G1 to $\mathrm{S}$ phase. In addition, Bcl-xl acts as an anti-apoptotic protein by preventing the release of cytochrome $\mathrm{c}$. Fas, a death receptor on the surface of cells, can lead to programmed cell death (32-37). In addition, the results of the present study are consistent with the above reports and the cytological features observed. Furthermore, the results suggest that these proteins may act as promising targets for the defected cytological features of BM-MSCs from patients with NMO. Moreover, the synergetic effects from two different proteins on the same cell signaling pathway may serve critical roles in that progress. However, whether there is a regulatory network or interaction between these proteins needs to be further investigated.

In conclusion, it has been demonstrated in the present study that, although the BM-MSCs from patients with NMO exhibited a similar cell morphology and differentiation ability when compared with the healthy controls, the cells grew more slowly and tended to be a little more inclined towards senescence. These aberrant changes in cytological features of patient-derived BM-MSCs could influence the therapeutic effects of autologous BM-MSC infusion treatment in NMO. Promising approaches to overcome the above-mentioned defects were to routinely add PDGF in vitro during the expansion phase of the BM-MSCs, or to combine PDGF cytokine therapy with BM-MSC infusion in refractory patients with NMO. Although the present study has provided a theoretical basis for treatment of $\mathrm{NMO}$, further studies are required in view of the limited number of patients with NMO. In addition, the immune modulatory and neurotrophic effects of these cells that were not included in this study also require further investigation.

\section{Acknowledgements}

The authors would like to thank Mr. Katherine Regan for editorial assistance.

\section{Funding}

The present study was funded by the National Natural Science Foundation of China (grant nos. 81371372, 81501031 and 81571172), the National Key Clinical Specialty Construction Program of China and the Natural Science Foundation of Tianjin (grant no. 15JCQNJC44800).

\section{Availability of data and materials}

The datasets used and/or analyzed during the current study are available from the corresponding author on reasonable request.

\section{Authors' contributions}

YYan, FDS and CY formulated the study concept and designed the project, GC, YYang and LM acquired the data, GC and CY analyzed and interpreted the data, GC, GXZ and FDS wrote and edited the paper. All authors read and approved the final manuscript.

\section{Ethics approval and consent to participate}

Informed consent was obtained from all participants in the present study and the study was approved by the Tianjin Medical University General Hospital Institutional Review Board and Ethics Committee (Tianjin, China).

\section{Patient consent for publication}

Each participant provided written informed consent. 


\section{Competing interests}

The authors declare they have no competing interests.

\section{References}

1. Jarius S and Wildemann B: Aquaporin-4 antibodies (NMO-IgG) as a serological marker of neuromyelitis optica: A critical review of the literature. Brain Pathol 23: 661-683, 2013.

2. Vodopivec I, Matiello M and Prasad S: Treatment of neuromyelitis optica. Curr Opin Ophthalmol 26: 476-483, 2015.

3. Wingerchuk DM, Pittock SJ, Lucchinetti CF, Lennon VA and Weinshenker BG: A secondary progressive clinical course is uncommon in neuromyelitis optica. Neurology 68: 603-605, 2007.

4. Kitley J, Leite MI, Nakashima I, Waters P, McNeillis B, Brown R, Takai Y, Takahashi T, Misu T, Elsone L, et al: Prognostic factors and disease course in aquaporin- 4 antibody-positive patients with neuromyelitis optica spectrum disorder from the United Kingdom and Japan. Brain 135: 1834-1849, 2012.

5. Wingerchuk DM and Weinshenker BG: Neuromyelitis optica: Clinical predictors of a relapsing course and survival Neurology 60: 848-853, 2003.

6. Cabre P, González-Quevedo A, Bonnan M, Saiz A, Olindo S, Graus F, Smadja D, Merle H, Thomas L and Cabrera-Gomez JA Relapsing neuromyelitis optica: Long term history and clinical predictors of death. J Neurol Neurosurg Psychiatry 80: 1162-1164, 2009.

7. Watanabe S, Nakashima I, Misu T, Miyazawa I, Shiga Y, Fujihara K and Itoyama Y: Therapeutic efficacy of plasma exchange in NMO-IgG-positive patients with neuromyelitis optica. Mult Scler 13: 128-132, 2007.

8. De Miguel MP, Fuentes-Julián S, Blázquez-Martínez A, Pascual CY, Aller MA, Arias J and Arnalich-Montiel F: Immunosuppressive properties of mesenchymal stem cells: Advances and applications. Curr Mol Med 12: 574-591, 2012

9. Eckert MA, Vu Q, Xie K, Yu J, Liao W, Cramer SC and Zhao W: Evidence for high translational potential of mesenchymal stromal cell therapy to improve recovery from ischemic stroke. J Cereb Blood Flow Metab 33: 1322-1334, 2013.

10. Zhang X, Bowles AC, Semon JA, Scruggs BA, Zhang S Strong AL, Gimble JM and Bunnell BA: Transplantation of autologous adipose stem cells lacks therapeutic efficacy in the experimental autoimmune encephalomyelitis model. PLoS One 9: e85007, 2014.

11. LiD, ChaiJ,ShenC,Han Y andSunT:Human umbilical cord-derived mesenchymal stem cells differentiate into epidermal-like cells using a novel co-culture technique. Cytotechnology 66: 699-708, 2014.

12. Zacharek A, Shehadah A, Chen J, Cui X, Roberts C, Lu M and Chopp M: Comparison of bone marrow stromal cells derived from stroke and normal rats for stroke treatment. Stroke 41: 524-530, 2010

13. Cohen JA: Mesenchymal stem cell transplantation in multiple sclerosis. J Neurol Sci 333: 43-49, 2013.

14. El-Akabawy G and Rashed LA: Beneficial effects of bone marrow-derived mesenchymal stem cell transplantation in a non-immune model of demyelination. Ann Anat 198: 11-20, 2015.

15. Fu Y, Yan Y, Qi Y, Yang L, Li T, Zhang N, Yu C, Su L, Zhang R, Shen Y, et al: Impact of autologous mesenchymal stem cell infusion on neuromyelitis optica spectrum disorder: A pilot, 2-year observation study. CNS Neurosci Ther 22: 677-685, 2016.

16. Livak KJ and Schmittgen TD: Analysis of relative gene expression data using real-time quantitative PCR and the 2(-Delta Delta C(T)) method. Methods 25: 402-408, 2001.

17. Belotti D, Capelli C, Resovi A, Introna $M$ and Taraboletti $G$ : Thrombospondin-1 promotes mesenchymal stromal cell functions via TGF $\beta$ and in cooperation with PDGF. Matrix Biol 55: 106-116, 2016

18. Papadopoulos $\mathrm{N}$ and Lennartsson J: The PDGF/PDGFR pathway as a drug target. Mol Aspects Med 62: 75-88, 2018.

19. Chen W, Baylink DJ, Brier-Jones J, Neises A, Kiroyan JB, Rundle $\mathrm{CH}$, Lau KH and Zhang XB: PDGFB-based stem cell gene therapy increases bone strength in the mouse. Proc Natl Acad Sci USA 112: E3893-E3900, 2015.

20. Solchaga LA, Bendele A, Shah V, Snel LB, Kestler HK, Dines JS and Hee CK: Comparison of the effect of intra-tendon applications of recombinant human platelet-derived growth factor-BB, platelet-rich plasma, steroids in a rat achilles tendon collagenase model. J Orthop Res 32: 145-150, 2014
21. Lennon VA, Wingerchuk DM, Kryzer TJ, Pittock SJ, Lucchinetti CF, Fujihara K, Nakashima I and Weinshenker BG: A serum autoantibody marker of neuromyelitis optica: Distinction from multiple sclerosis. Lancet 364: 2106-2112, 2004.

22. Xiao J, Yang R, Biswas S, Qin X, Zhang $M$ and Deng W: Mesenchymal stem cells and induced pluripotent stem cells as therapies for multiple sclerosis. Int J Mol Sci 16: 9283-9302, 2015.

23. Greco R, Bondanza A, Vago L, Moiola L, Rossi P, Furlan R, Martino G, Radaelli M, Martinelli V, Carbone MR, et al: Allogeneic hematopoietic stem cell transplantation for neuromyelitis optica. Ann Neurol 75: 447-453, 2014

24. Matiello M, Pittock SJ, Porrata L and Weinshenker BG: Failure of autologous hematopoietic stem cell transplantation to prevent relapse of neuromyelitis optica. Arch Neurol 68: 953-955, 2011.

25. Wilkins A, Kemp K, Ginty M, Hares K, Mallam E and Scolding N: Human bone marrow-derived mesenchymal stem cells secrete brain-derived neurotrophic factor which promotes neuronal survival in vitro. Stem Cell Res 3: 63-70, 2009.

26. Cramer SC, Sur M, Dobkin BH, O'Brien C, Sanger TD, Trojanowski JQ, Rumsey JM, Hicks R, Cameron J, Chen D, et al: Harnessing neuroplasticity for clinical applications. Brain 134: 1591-1609, 2011.

27. Lee JS, Hong JM, Moon GJ, Lee PH, Ahn YH, Bang OY and STARTING collaborators: A long-term follow-up study of intravenous autologous mesenchymal stem cell transplantation in patients with ischemic stroke. Stem Cells 28: 1099-1106, 2010.

28. Connick P, Kolappan M, Crawley C, Webber DJ, Patani R, Michell AW, Du MQ, Luan SL, Altmann DR, Thompson AJ, et al: Autologous mesenchymal stem cells for the treatment of secondary progressive multiple sclerosis: An open-label phase 2a proof-of-concept study. Lancet Neurol 11: 150-156, 2012.

29. Park HJ, Shin JY, Lee BR, Kim HO and Lee PH: Mesenchymal stem cells augment neurogenesis in the subventricular zone and enhance differentiation of neural precursor cells into dopaminergic neurons in the substantia nigra of a parkinsonian model. Cell Transplant 21: 1629-1640, 2012.

30. Danielyan L, Schäfer R, von Ameln-Mayerhofer A, Bernhard F, Verleysdonk S, Buadze M, Lourhmati A, Klopfer T, Schaumann F, Schmid B, et al: Therapeutic efficacy of intranasally delivered mesenchymal stem cells in a rat model of Parkinson disease. Rejuvenation Res 14: 3-16, 2011.

31. Lu Z, Ye D, Qian L, Zhu L, Wang C, Guan D, Zhang X and $\mathrm{Xu}$ Y: Human umbilical cord mesenchymal stem cell therapy on neuromyelitis optica. Curr Neurovasc Res 9: 250-255, 2012.

32. Zaiss DMW, Gause WC, Osborne LC and Artis D: Emerging functions of amphiregulin in orchestrating immunity, inflammation, and tissue repair. Immunity 42: 216-226, 2015.

33. Jeon $\mathrm{H}$ and Boo YC: Senescent endothelial cells are prone to TNF- $\alpha$-induced cell death due to expression of FAS receptor. Biochem Biophys Res Commun 438: 277-282, 2013.

34. Ols ML, Cullen JL, Turqueti-Neves A, Giles J and Shlomchik MJ: Dendritic cells regulate extrafollicular autoreactive B cells via T cells expressing Fas and Fas ligand. Immunity 45: 1052-1065, 2016.

35. Cruz AC, Ramaswamy M, Ouyang C, Klebanoff CA, Sengupta $P$, Yamamoto TN, Meylan F, Thomas SK, Richoz N, Eil R, et al: Fas/CD95 prevents autoimmunity independently of lipid raft localization and efficient apoptosis induction. Nat Commun 7: 13895, 2016.

36. Ikezawa K, Hikita H, Shigekawa M, Iwahashi K, Eguchi H, Sakamori R, Tatsumi T and Takehara T: Increased Bcl-xL expression in pancreatic neoplasia promotes carcinogenesis by inhibiting senescence and apoptosis. Cell Mol Gastroenterol Hepatol 4: 185-200 e181, 2017.

37. Aouacheria A, Baghdiguian S, Lamb HM, Huska JD, Pineda FJ and Hardwick JM: Connecting mitochondrial dynamics and life-or-death events via $\mathrm{Bcl}-2$ family proteins. Neurochem Int 109: 141-161, 2017.

38. Huang Y and Dreyfus CF: The role of growth factors as a therapeutic approach to demyelinating disease. Exp Neurol 283: 531-540, 2016.

This work is licensed under a Creative Commons Attribution-NonCommercial-NoDerivatives 4.0 International (CC BY-NC-ND 4.0) License. 